\title{
Duração das fases de cultivo de cebola da variedade Empasc 352 - Bola Precoce em clima Subtropical de Ituporanga, Santa Catarina
}

Hamilton Justino Vieira' ${ }^{1}$ Francisco Olmar Gervini de Menezes Junior ${ }^{2}$, Everton Blainski ${ }^{3}$, Joelma Miszinski ${ }^{4}$ e João Vieira Neto ${ }^{5}$

Resumo - O objetivo do trabalho foi avaliar os padrões fenológicos do cultivar de cebola Empasc 352 - Bola Precoce, quando submetido às diferentes condições climáticas e fotoperiódicas do clima subtropical de Santa Catarina, SC, Brasil. Os tratamentos consistiram em 10 épocas de semeaduras, distanciadas em uma semana, repetidas no período 15/03 a 17/05 durante quatro anos. A partir dos resultados observou-se uma relação, não linear, entre as datas de semeadura e a duração em dias até o transplante, representada por um polinômio de segundo grau. As datas mais tardias de semeaduras apresentam um significativo aumento na duração semeadura-transplante. À medida em que as épocas de semeaduras foram postergadas ocorreu uma diminuição do período entre transplante-colheita. A relação entre a duração da fase semeadura-transplante e transplante-colheita foi inversa, ou seja, maior duração da fase semeadura-transplante e menor na transplante-colheita. Conclui-se, portanto, que a data de semeadura exerce efeito na variação da duração do ciclo da cebola. Cada dois dias de avanço na data de semeadura correspondeu em três dias na data de transplante.

Termos para indexação: Allium cepa; épocas de semeadura; fenologia.

\section{Duration of the onion growing stages of the Empasc 352 - Bola Precoce variety in a subtropical climate of Ituporanga, Santa Catarina}

Abstract - The objective of the work was to evaluate the phenological patterns of the onion cultivar Empasc 352 - Bola Precoce, when submitted to different climatic and photoperiodic conditions of the subtropical climate of Santa Catarina, SC, Brazil. The treatments consisted of 10 sowing times, separated by one week, repeated from 03/15 to 05/17 for four years. From the results, a non-linear relationship was observed between the sowing dates and the duration in days until transplantation, represented by a second-degree polynomial regression. The later sowing dates showed a significant increase in the sowingtransplant duration. As the sowing seasons were postponed, there was a decrease in the period between transplant-harvest. The relationship between the duration of the sowing-transplant and transplant-harvest phase was reversed, that is, a longer duration of the sowing-transplant phase and shorter in the transplant-harvest phase. It is concluded, therefore, that the sowing date is important for the onion cycle duration. Every two days of advance on the sowing date corresponded to three days on the transplant date.

Index terms: Allium cepa; sowing times; phenology.

\section{Introdução}

Santa Catarina caracteriza-se pela grande variação de relevo, altitudes, tipos de solos e diversidade climática. Este mosaico de fatores direcionaram o Estado para a agricultura familiar, tendo a cebola como a principal espécie olerácea sob cultivo, posicionando-o como o principal produtor nacional desta hortaliça. Na safra de 2019/20, Santa
Catarina produziu mais de 532 mil toneladas em $18.182 \mathrm{ha}$, com produtividade média de 29,26t ha-1. Em comparação à safra anterior, embora tenha havido decréscimo na área cultivada de 4,27\%, verificou-se elevação da produtividade e da produção, que aumentaram em $14,38 \%$ e $9,68 \%$, respectivamente (EPAGRI/CEPA, 2020).

O Alto Vale do Itajaí é reconhecido como a principal região produtora de Santa Catarina, que é uma das maiores fornecedoras do produto para o mercado nacional (EPAGRI/CEPA, 2020). A localização desta região proporciona que a colheita e a comercialização sejam feitas na "janela" entre a produção de outras regiões e estados, tais com São Paulo, Bahia, Minas Gerais e Rio Grande do Sul.

Para Lisbão (1986) e Sirtoli (2010), a cebola é fortemente influenciada por fatores climáticos e ambientais que condicionam a adaptação de um cul-»

Recebido em 23/7/2020. Aceito para publicação em 4/2/2021.

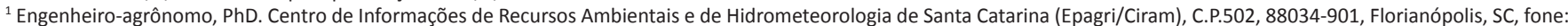
(048) 3665 5006, e-mail:vieira@epagri.sc.gov.br

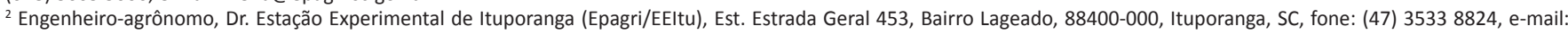
franciscomenezes@epagri.sc.gov.br

${ }^{3}$ Engenheiro-agrônomo, Dr. Centro de Informações de Recursos Ambientais e de Hidrometeorologia de Santa Catarina ((Epagri/Ciram), e-mail: evertonblainski@epagri.sc.gov.br

${ }^{4}$ Analista de Sistemas, BSc. Centro de Informações de Recursos Ambientais e de Hidrometeorologia de Santa Catarina (Epagri/Ciram), e-mail: joelma@epagri.sc.gov.br

${ }^{5}$ Engenheiro-agrônomo, Dr. Estação Experimental de Ituporanga (Epagri/EEltu), e-mail: joaoneto@epagri.sc.gov.br 
tivar a determinada região geográfica. Concordando com estes autores, Ruiter (1986) e Carline (2017) afirmam que a influência do fotoperíodo e da temperatura sobre o desenvolvimento da cebola é dinâmica e dependente do cultivar. $\mathrm{O}$ plantio de cultivares não adaptados à região produtora pode resultar em safras frustrantes, pois a cebola requer condições próprias para a completa bulbificação (CARLINE, 2017).

Neste contexto, o objetivo do trabaIho foi estudar padrões fenológicos do cultivar de cebola Empasc 352 - Bola Precoce quando submetido a diferentes condições climáticas e fotoperiódicas.

\section{Material e métodos}

O trabalho foi conduzido na Estação Experimental de Ituporanga (Epagri/ EEltu), SC, latitude de 27응' S, longitude de 4960' W e altitude média de 475 metros acima do nível do mar, durante as safras agrícolas de 2010, 2011, 2012 e 2013.

Segundo a classificação de Köeppen, o clima local é do tipo Cfa. O cultivar utilizado, que prevalece em mais de $60 \%$ da área de cebola cultivada no estado de Santa Catarina, foi o Empasc 352 - Bola Precoce. O solo da área experimental foi classificado como Cambissolo Háplico de textura argilosa. As mudas foram produzidas com base nos referenciais tecnológicos propostos pelo Sistema de Produção para a Cebola (EPAGRI, 2013).

Os tratamentos consistiram em 10 épocas de semeadura, em período semanal, de 15 de março a 17 de maio, durante quatro anos de 2010, 2011, 2012 e 2013. Os transplantes foram efetuados quando $70 \%$ das mudas atingiam um diâmetro do bulbilho de aproximadamente aproximado de $0,5 \mathrm{~cm}$ e 5 folhas.

A adubação seguiu as recomendações da Comissão de Química de Fertilidade do Solo - RS/SC (2004). A colheita foi realizada quando do tombamento do pseudocaule ("estalo") de aproximadamente $70 \%$ das plantas nas parcelas experimentais foi atingido. Para o estudo dividiu-se o ciclo total nas seguintes fases fenológicas: semeadura ao transplante, transplante à maturação e semeadura à maturação.

Tabela 1.

O delineamento experimental foi inteiramente casualizado, com quatro repetições (parcelas) para cada data de semeadura e ano de cultivo. As parcelas experimentais foram formadas por sete linhas de 3,0m de comprimento, espaçadas $0,40 \mathrm{~m}$, com área total de $8,4 \mathrm{~m}^{2} \mathrm{e}$ área útil de $4,0 \mathrm{~m}^{2}$. Os efeitos das datas de semeadura sobre a duração em dias das diferentes fases fenológicas foram estudados através de análise de regressão, utilizando-se o software Excel e a média de quatro repetições para cada época de semeadura para as 10 épocas de semeaduras em cada ano, somando ao todo 37 épocas de semeaduras nos quatro anos de experimento.

\section{Resultados e discussão}

Na Figura 1 (a), (b), (c) e (d), pode ser observada a duração das fases fenológicas da cebola segundo as datas de semeadura e os anos. Os transplantes foram realizados em maio, junho, julho e agosto. Durante a condução do experimento as temperaturas médias mensais do período de semeadura foram as mais baixas do ano, tendo a ordem decrescente maio, $15,2^{\circ} \mathrm{C}$, junho, $13,4^{\circ} \mathrm{C}$ e julho $12,7^{\circ} \mathrm{C}$. As plântulas semeadas em março tiveram seu desenvolvimen- to condicionado às condições climáticas de abril e maio, enquanto aquelas correspondentes a abril, às temperaturas invernais, de maio e junho. As semeaduras de maio desenvolveram-se nos meses de junho, julho e parte de agosto. Considerando-se que as semeaduras foram igualmente espaçadas entre si, a diferença de duração nesta fase denota que as condições ambientais influenciaram o desenvolvimento das plântulas neste período de transplante. Nota-se claramente que as semeaduras tardias provocaram um aumento da duração da fase semeadura-transplante. Em contrapartida, durante o desenvolvimento nos canteiros definitivos do transplante à colheita, observou-se uma clara diminuição da duração desta fase para as épocas mais tardias. Os valores mínimos de 91 dias em 2011 para a primeira época e máximo de 198 dias em 2013 para a décima época indicam tal tendência.

Ao observar as datas de colheita nas diversas épocas e anos de avaliação, nota-se que as épocas 9 e 10 resultaram numa colheita mais tardia quando comparadas às demais. A postergação da data de colheita pode estar associada a temperaturas mais elevadas nos períodos que aumentam a incidência de tripes e impedem o tombamento natural ("estalo") e, por conseguinte, a identificação do ponto de colheita (LORINI \& DEZORDI, 1990).

Na Figura 2 é apresentada a evolução da fase semeadura-transplante com as influências interanuais. A partir do final de abril e no mês de maio ocorre uma tendência de aumento da duração desta fase. As últimas épocas de semeaduras, efetuadas no mês de maio (8a, 9a e 10a épocas), apresentam os maiores valores de duração desta fase, alcançando valores de 80 ou mais dias. Em 2013

Tabela 1. Médias mensais da temperatura durante os quatro anos de 2010, 2011, 2012 e 2013

Table 1. Monthly temperature averages during the four years of 2010, 2011, 2012 and 2013

\begin{tabular}{c|ccccccccccrrr}
\hline Meses & Jan & Fev & Mar & Abr & Mai & Jun & Jul & Ago & Set & Out & Nov & Dez \\
\hline $\mathrm{T}^{\circ} \mathrm{C}$ & 22,2 & 23,0 & 20,7 & 18,2 & 15,2 & 13,4 & 12,7 & 14,2 & 15,9 & 18,1 & 19,6 & 21,6 \\
\hline
\end{tabular}



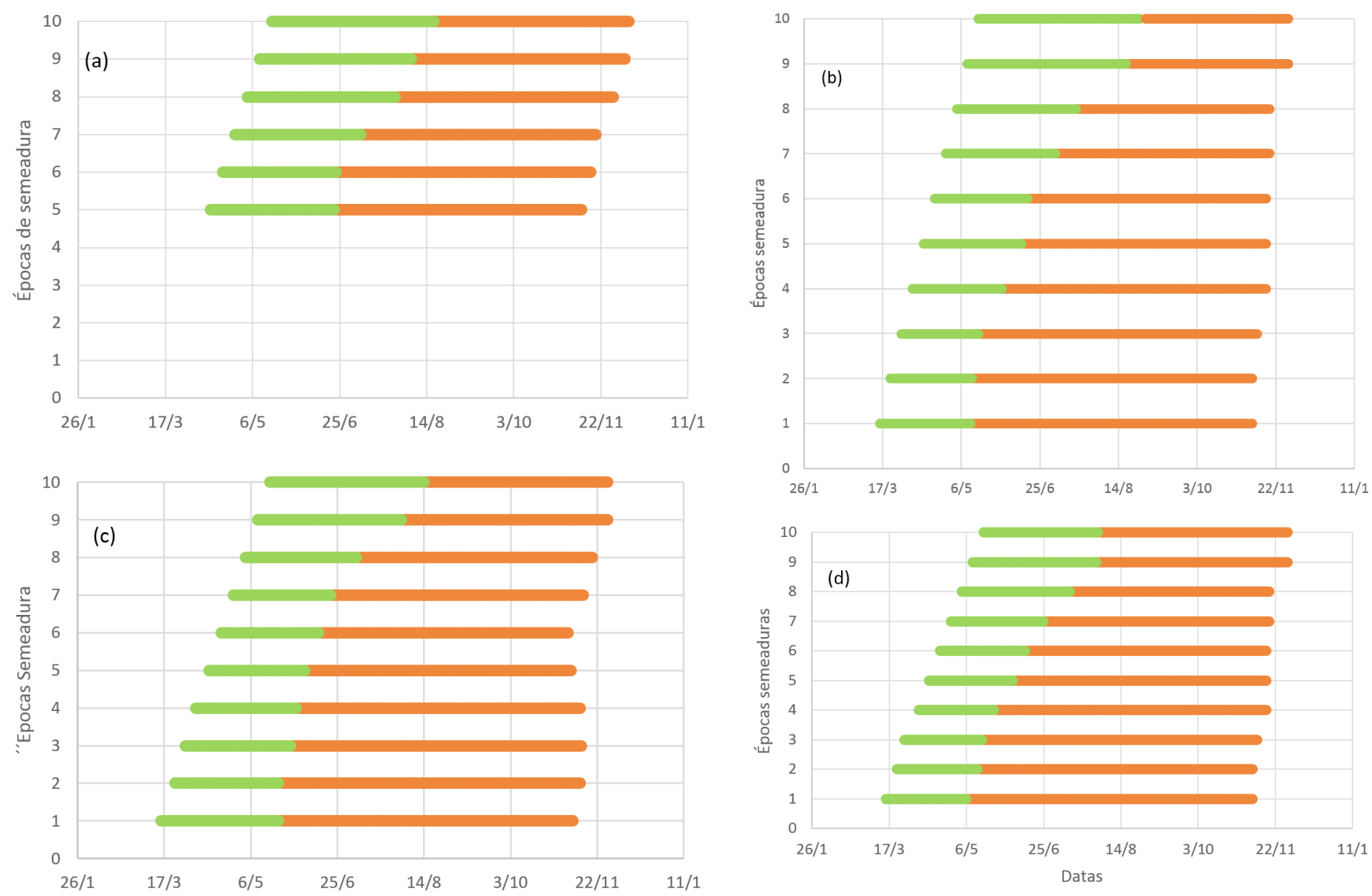

Figura 1. Datas de ocorrência das fases de semeadura, transplante e colheita e a duração em dias das fases semeadura-transplante $(*)$, transplante-colheita (*) e semeadura-colheita do cultivar Bola Precoce nos anos de 2010, 2011, 2012 e 2013 em Ituporanga, SC Figure 1. Dates of occurrence of the sowing, transplant and harvest phases and the duration in days of the sowing-transplant $(*)$, transplant-harvest (*) and sowing-harvest phases of the cultivar Bola Precoce in the years 2010, 2011, 2012 and 2013 in Ituporanga, SC

ocorreram as menores durações desta fase em quase todas as épocas de semeadura. Apesar da dispersão da duração desta fase em cada época de semeadura e para os anos de observação, a tendência de aumento da fase é evidente quando se observa a equação representativa desta variação $y=0,00167 x^{2}$ $0,53658 x+58,914\left(R^{2}=0,7445\right)$. A data de semeadura explica $74 \%$ da variação da duração desta fase. Como a cultura é dependente do fotoperíodo, salienta-se que as épocas com menor duração desta fase tiveram desenvolvimento inicial antes de 24/04, com fotoperíodo acima de 12 horas. Isso pode ser um dos fatores que determinam a duração desta fase. Contudo, as temperaturas podem também influenciar significativamente o desenvolvimento das plântulas.

$\mathrm{Na}$ Figura 3 são apresentadas as relações das datas de semeadura e as durações das três fases observadas.

\section{Duração semeadura-transplante}

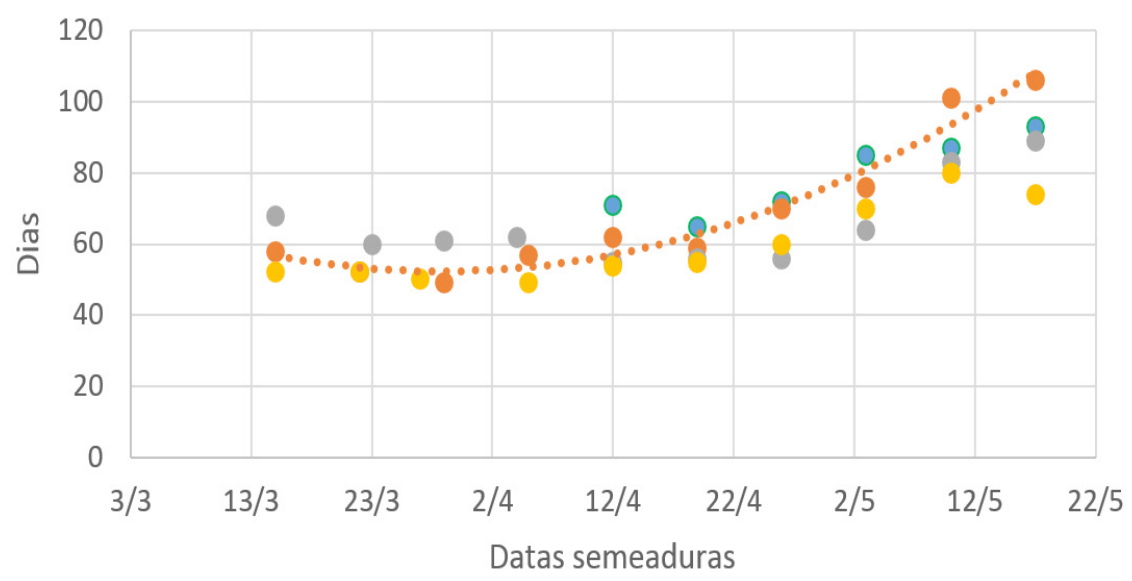

Ano 2010 Ano 2011 Ano 2012 Ano 2013

Figura 2. Relação entre as datas de semeadura e a duração do período entre semeadura e transplante do cultivar Empasc 352 - Bola Precoce para 10 épocas de semeaduras nos anos de 2010, 2011, 2012 e 2013 em Ituporanga, SC

Figure 2. Relationship between sowing dates and the length of the period between sowing and transplanting the cultivar Empasc 352 - Bola Precoce for 10 sowing seasons in the years 2010, 2011, 2012 and 2013 in Ituporanga, SC 


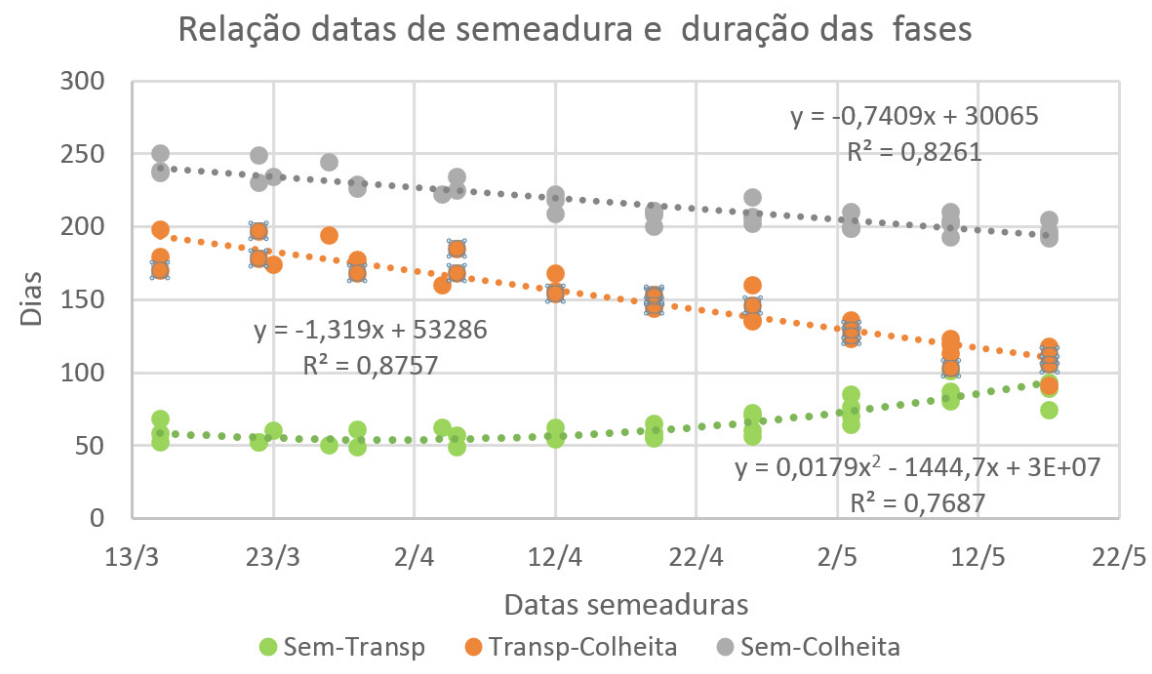

Figura 3. Relação entre data de semeadura e a duração em dias das fases de semeaduratransplante, transplante-colheita e semeadura-colheita do cultivar Empasc 352 - Bola Precoce nos anos de 2010, 2011, 2012 e 2013 em Ituporanga, SC

Figure 3. Relationship between sowing date and duration in days of the sowing-transplant, transplant-harvest and sowing-harvest phases of the cultivar Empasc 352 - Bola Precoce in the years 2010, 2011, 2012 and 2013 in Ituporanga, SC

Para a fase de semeadura-transplante observou-se uma amplitude da duração de aproximadamente 50 dias entre as primeiras épocas e as últimas épocas de semeadura. Para as semeaduras de 15 de março (dia primeiro), o transplante ocorreu 55 dias após, e semeaduras em 17/05 a duração foi de aproximadamente 100 dias.

Para a fase transplante-maturação a amplitude da duração foi de aproximadamente 100 dias, com os valores máximos de 200 dias para semeaduras de março e 100 dias para as últimas semeaduras de abril.

Para a fase de semeadura-colheita a amplitude foi de aproximadamente 50 dias, com valores máximos e mínimos de 200 e 250, respectivamente. Enquanto a fase semeadura-transplante apresentou tendência de aumento da duração, as demais apresentaram a tendência de diminuição frente ao atraso das datas de semeadura. A maior variação entre épocas foi a fase transplantecolheita com valor de aproximadamente 100 dias. Estas variações de duração das fases e ou ciclo da cultura da cebola foram também observadas por Lisbão et al. (1985) e Ruiter (1986). Ao testar épocas de semeadura para diferentes cultivares os autores observaram que houve a diminuição do ciclo dos cultivares à medida que se atrasou a sua semeadura. No Brasil, Carline et al. (2017), ao pesquisarem a influência de épocas de semeadura para três cultivares no Centro-Sul do estado do Tocantins, ve- rificaram uma variação média de 182 a 80 dias. Sirtoli et al. (2010), ao testarem três cultivares e três épocas de semeadura em Marechal Cândido Rondon, PR, observaram uma diminuição do ciclo de 150 para 80 dias.

Na Figura 4 é apresentada uma síntese da influência da duração da fase de semeadura sobre a duração da fase de transplante-colheita. Como a data de colheita é relativamente estável (RUITER,1986), verifica-se que o aumento da fase entre a semeadura-transplante causa uma diminuição da fase transplante-colheita. Para uma diferença de aproximadamente 60 dias para a fase semeadura transplante a diminuição da fase transplante-colheita pode alcançar o valor de 100 dias. Esta relação pode ser explicada pela equação $Y=-1,6685 x$ $+260,11 R^{2}=0,793$, onde o " $x$ " é a duração da fase semeadura-transplante.

Os dois polinômios que representam a variação percentual das duas fases na Figura 5 são complementares. Quando se observa o módulo dos termos, verifica-se que são idênticos, pois a soma das percentagens para determinada época de semeadura matematicamente é $100 \%$. Conforme Lisbão et al. (1985), Ruiter (1986), Carline et al. (2017) e Sir-

\section{Transplante-colheita e Transplante-Colheita}

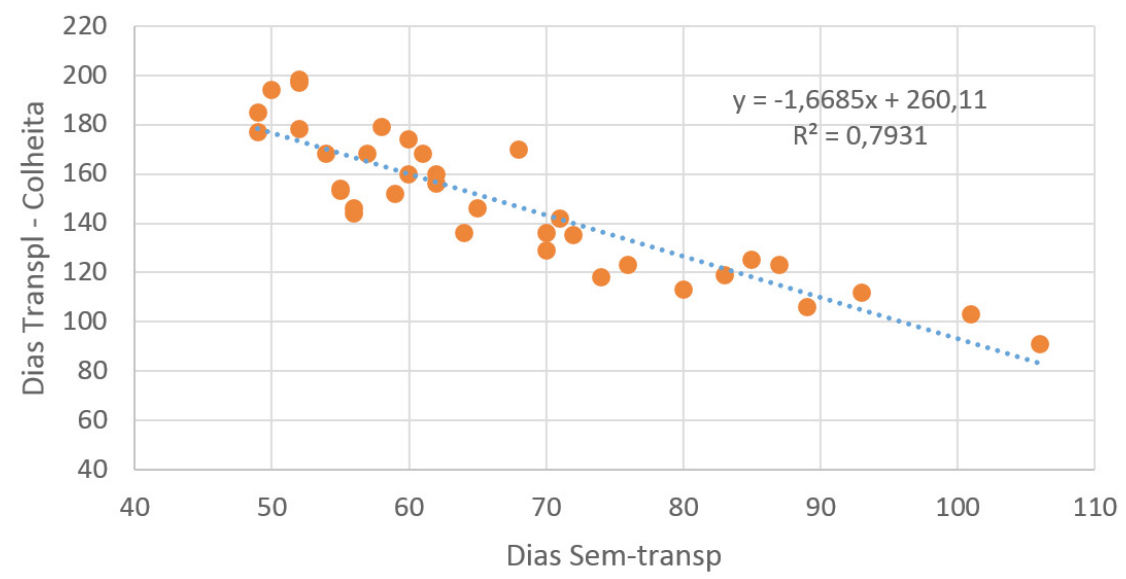

Figura 4. Relação entre a duração do período de semeadura transplante e a duração do período entre transplante e colheita para 10 épocas de semeadura nos anos de 2010, 2011, 2012 e 2013 do cultivar Empasc 352 - Bola Precoce em Ituporanga, SC

Figure 4. Relationship between the length of the transplant sowing period and the length of the period between transplant and harvest for 10 sowing seasons in the years 2010, 2011, 2012 and 2013 of the cultivar Empasc 352 - Bola Precoce in Ituporanga, SC 


\section{Percentagem duração das fases}

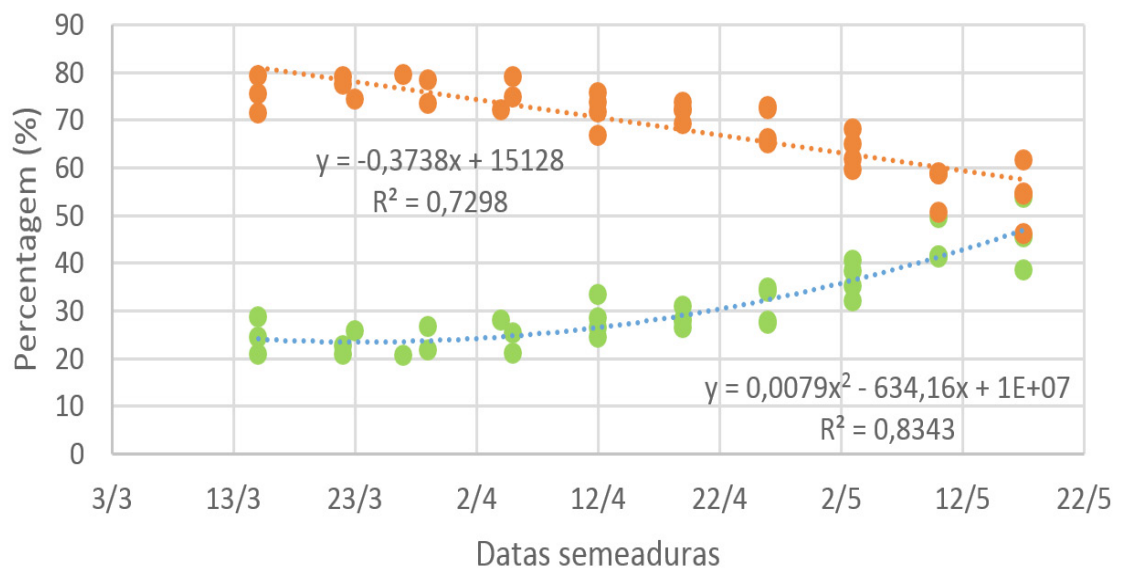

- Sem-transp OTransp-Colheita

Figura 5. Variação em percentagem das durações da fases semeadura-transplante e transplante-maturação em função das datas de semeaduras tendo com denominador a duração da fase semeadura-maturação do cultivar Empasc 352 - Bola Precoce para os anos 2010, 2011, 2012 e 2013 em Ituporanga, SC

Figure 5. Variation in percentage of the durations of the sowing-transplanting and transplanting-maturation phases according to the sowing dates with the denominator the duration of the sowing-maturation phase of the cultivar Empasc 352 - Bola Precoce for the years 2010, 2011, 2012 and 2013 in Ituporanga, SC

toli et al. (2010), a postergação da semeadura provoca diminuição do ciclo. $\mathrm{O}$ atraso do transplante, portanto, faz diminuir a percentagem da fase transplante-colheita. A convergência das duas curvas ao final do período de semeaduras é consequência do aumento da fase semeadura-transplante e uma diminuição da fase transplante-maturação, já que as datas de maturação apresentam baixa variação quando comparadas com as demais fases. $O$ valor igualitário de $50 \%$ para cada fase no final do mês de abril indica que as plântulas permaneceram no canteiro de semeadura um período em dias igual àquele que as plantas tiveram para o desenvolvimento de bulbos até atingirem a maturação. A importância desta variação percentual ao longo do período de semeadura é que a postergação das datas de semeaduras provoca um aumento da percentagem da fase semeadura-transplante em detrimento da fase subsequente transplante-maturação.

\section{Conclusões}

- As fases épocas de transplante-coIheita são influenciadas pelas datas de semeaduras.

- A relação entre a duração da fase semeadura-transplante e transplante-colheita é inversa, ou seja, quanto transplante, menores as fases de transplante-colheita;

- A data de semeadura foi a principal responsável pela variação da duração do ciclo da cebola.

\section{Referências}

BETTONI, M. M.; MÓGOR, À., F.; DECHAMPS, C.; DA SILVA, V. C. P.; MARIANE DANIELE SASS, M., D.; FABBRIN, E. G. S. Crescimento e produção de sete cultivares de cebola em sistema orgânico em plantio fora de época Semeadura: Ciências Agrarias, Londrina, v.34, n.5, p.2139-2152. 2013.

CARLINE, J. V. G.; TAVARES, A. T.; FREITAS, J. A.; MILHOMENS, K. K. B.; NASCIMENTO, maiores durações da fase semeadura-

I. R. Épocas de cultivo de cebola no Centro Sul do estado do Tocantins. Brazilian Journal of Applied Technology for Agricultural Science, Guarapuava-PR, v.10, n.2, p.33-42, 2017. DOI: https://doi.org/10.5935/PAeT. v10n.2.3.

CQFS - RS/SC - COMISSÃO DE QUÍMICA E FERTILIDADE DO SOLO RS/SC - CQFS-RS/SC. Manual de adubação e de calagem para o Estado do Rio Grande do Sul e Santa Catarina. Porto Alegre: UFRGS, 2004. 400p.

EPAGRI/CEPA. Cebola. In: Efeitos socioeconômicos da estiagem e da pandemia do novo coronavírus sobre a produção agropecuária de Santa Catarina. Maio/2020. Florianópolis, 2020, p.35. (Epagri. Documentos, 310). 42p. Disponivel em: https://docweb. epagri.sc.gov.br/website_cepa/publicacoes/ Efeitos_socieconomicos_da_estiagem_e_ pandemia.pdf. Acesso em: 03 maio 2020.

EPAGRI. Sistema de produção para a cebola: Santa Catarina. (4. Revisão). Florianópolis: 2013. 106p. (Epagri. Sistemas de Produção, 46). Disponivel em: https://ciram.epagri. sc.gov.br/ciram_arquivos/cebola/acervo/ sistema_producao_cebola_sc.pdf . Acesso em: 03 maio 2020.

LISBÃO, R. S.; FORNASIER, J. B.; IGUE, T; CURY, A. P. Avaliação de Cultivares de Cebola em Diferentes Épocas de Semeadura em Monte Alegre do Sul. Bragantia, Campinas, v. 44, n.1, p.441-450, 1985. DOI: https://doi. org/10.1590/s0006-87051985000100041.

RINI, I.; DEZORDI, J. Flutuação populacional de Thrips tabaci (Lindeman, 1888) (Thysanoptera - Thripidae) na cultura da cebola. Anais da Sociedade Entomológica do Brasil, v.19, n.2, p.361-365, 1990.

SIRTOLI, M. F.; FURLAN, L.; RODRIGUES, J. D. Avaliação de cultivares de cebola para conserva em diferentes épocas de semeadura em Marechal Cândido Rondon - PR. Scientia Agraria Paranaensis v.9, n.1, p.5 - 14, 2010. DOI: https://doi.org/10.18188/sap. v9i1.4267.

RUITER, J. M. The effects of temperature and photoperiod on onion bulb growth and development. Proceedings Agronomy Society of N.Z. v.16, p.93-100, 1986. Disponível em: https://www.agronomysociety.org.nz/1986journal-papers.html. Acesso em: 20 julho 2020 . 